\title{
Intelligent Photovoltaic Maximum Power Point Tracking Controller for Energy Enhancement in Renewable Energy System
}

\author{
Subiyanto, ${ }^{1}$ Azah Mohamed, ${ }^{2}$ and M. A. Hannan ${ }^{2}$ \\ ${ }^{1}$ Faculty of Engineering, Semarang State University, Semarang 50229, Indonesia \\ ${ }^{2}$ Universiti Kebangsaan Malaysia and Persiaran Universiti, 43600 Bandar Baru Bangi, Selangor, Malaysia \\ Correspondence should be addressed to Subiyanto; biyantote_unnes@yahoo.com
}

Received 19 November 2012; Revised 18 February 2013; Accepted 18 February 2013

Academic Editor: Onder Ozgener

Copyright (c) 2013 Subiyanto et al. This is an open access article distributed under the Creative Commons Attribution License, which permits unrestricted use, distribution, and reproduction in any medium, provided the original work is properly cited.

\begin{abstract}
Photovoltaic (PV) system is one of the promising renewable energy technologies. Although the energy conversion efficiency of the system is still low, but it has the advantage that the operating cost is free, very low maintenance and pollution-free. Maximum power point tracking (MPPT) is a significant part of PV systems. This paper presents a novel intelligent MPPT controller for PV systems. For the MPPT algorithm, an optimized fuzzy logic controller (FLC) using the Hopfield neural network is proposed. It utilizes an automatically tuned FLC membership function instead of the trial-and-error approach. The MPPT algorithm is implemented in a new variant of coupled inductor soft switching boost converter with high voltage gain to increase the converter output from the PV panel. The applied switching technique, which includes passive and active regenerative snubber circuits, reduces the insulated gate bipolar transistor switching losses. The proposed MPPT algorithm is implemented using the dSPACE DS1104 platform software on a DS1104 board controller. The prototype MPPT controller is tested using an agilent solar array simulator together with a $3 \mathrm{~kW}$ real PV panel. Experimental test results show that the proposed boost converter produces higher output voltages and gives better efficiency (90\%) than the conventional boost converter with an RCD snubber, which gives $81 \%$ efficiency. The prototype MPPT controller is also found to be capable of tracking power from the $3 \mathrm{~kW}$ PV array about 2.4 times more than that without using the MPPT controller.
\end{abstract}

\section{Introduction}

Energy generation based on renewable energy resources has received a great attention. Photovoltaic (PV) system is one of the promising renewable energy technologies. The photovoltaic (PV) generation system is a promising renewable, clean, and environmentally friendly source of energy [1]. Each solar cell produces only about one-half volt of electricity, and dozens of individual solar cells are interconnected in a sealed, weatherproof package called a PV module [2]. PV modules can be connected in series, parallel, or both into what is called a PV array. This PV array is connected to a power conditioner and then to a load or grid tie as a grid connected PV system.

In general, the two main problems with PV power generation systems are the low conversion efficiency and that electrical power generated by a typical PV panel varies with weather conditions. Thus, many studies on enhancing the energy-generation efficiency of PV applications have been carried out [3]. A PV generation system should operate at its maximum power point (MPP) to increase system efficiency [4]. Therefore, MPP tracking (MPPT) is very crucial for PV power generation systems to operate at the maximum point as much as possible at any time. However, the MPP also changes with the irradiation level and temperature due to the nonlinear characteristics of PV modules [5]. To overcome this problem, many MPPT algorithms have been developed [6].

Recently, fuzzy logic has been applied in tracking the MPP of PV systems because it has the advantages of being robust, simple in design, and minimal requirement for accurate mathematical modeling $[7,8]$. However, fuzzy logic methods depend on a careful selection of parameters, definition of membership functions, and fuzzy rules. Developing fuzzy logic methods also requires expert knowledge and experimentation in selecting parameters and membership functions. For this reason, adaptive fuzzy logic control has 
TABLE 1: Fuzzy rules of the FLC for MPPT.

\begin{tabular}{lccccccc}
\hline \multirow{2}{*}{ Input-2 $\left(\Delta d^{k}\right)$} & & & \multicolumn{5}{c}{ Input-1 $\left(\Delta P_{\mathrm{PV}}^{k}\right)$} \\
& $\mathrm{NL}$ & $\mathrm{NM}$ & $\mathrm{NS}$ & ZE & PS & PM & PL \\
\hline $\mathrm{N}$ & PLL & PL & PM & PS & NM & NL & NLL \\
ZE & NL & NM & NS & ZE & PS & PM & PL \\
$\mathrm{P}$ & NLL & NL & NM & NS & PM & PL & PLL \\
\hline
\end{tabular}

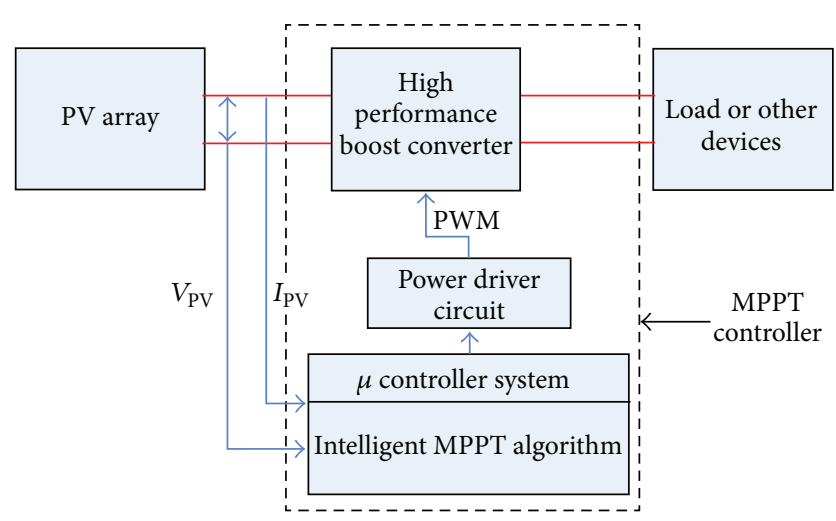

FIGURE 1: Schematic diagram of the proposed intelligent MPPT controller.

been developed by adding an inverse fuzzy knowledge base [9], parameter tuning of fuzzy logic control by optimization techniques such as genetic algorithms [10], and particle swarm optimization [11]. A number of studies on MPPT have also concentrated on the application of artificial neural networks (ANN) [12]. In most ANN-based MPPT methods, large amounts of field data considering atmospheric conditions are required to train the ANN. The main drawback of ANN-based MPPT methods is that it is system dependent and requires time-consuming implementation of PV arrays with different characteristics. Thus, MPPT algorithms are not robust against the rapidly changing temperature and irradiation, as well as partial shading. For the purpose of developing a more robust MPPT algorithm, a new type of intelligent technique based on the Hopfield neural network (HNN) is proposed and used together with a fuzzy logicbased MPPT controller in a PV system. Here, the fuzzy logic MPPT controller is integrated with the HNN to optimize the membership function of the fuzzy system.

In any PV system, the MPP of a PV module is tracked by the MPPT algorithm and a DC-DC boost converter, which is controlled by a triggering signal with a specific duty cycle to trigger the switch of the converter and locate its operating point as closely as possible to its MPP. Boost converter with MPPT plays an important role in PV power systems because it maximizes the power output from a PV system under various conditions, thereby maximizing the PV array efficiency. To improve the boost conversion efficiency, many modified boost converter topologies have been developed. Conventional boost converters operate in the hard-switching mode, thus rendering it inefficient when voltages and currents in semiconductor switching devices are changed abruptly from high values to zero and vice versa at turn-on and turn-off times. Consequently, switching losses and electromagnetic interference occur [13]. An improved boost converter topology using a coupled inductor together with a passive snubber has been developed and applied in standalone PV [14] and grid-connected PV systems [15]. Considering these facts, a new variant of a high gain, softswitching DC-DC converter is proposed in to reduce the number of series-connected PV modules and improve the conversion efficiency.

\section{New Boost Converter for MPPT Controller in a PV System}

2.1. System Description. The MPPT controller together with a boost converter is connected between the PV panel and load, as shown in Figure 1. Here, an MPPT algorithm to draw current controls the boost converter or voltage at the MPP thus maximum power available from the PV is delivered to the load. The intelligent MPPT algorithm is used to enhance the MPPT controller performance.

2.2. High-Performance Boost Converter. The circuit diagram of the proposed boost converter for the MPPT of a PV system is depicted in Figure 2. It comprises six parts: a source with an input filter (part 1), a primary side circuit (part 2), a secondary side circuit (part 3), a snubber circuit (parts $4 \mathrm{a}$ and 4b), an output filter with load (part 5), and a pulse width modulation (PWM) control mechanism (part 6). The detailed components of the converter represented by the respective symbols are described according to the various parts of the circuit.

The input filter and primary circuit with source power are represented as follows: DC input voltage from PV panel $\left(V_{\text {in }}\right)$, DC input current from PV panel $\left(I_{\text {in }}\right)$, capacitor of input filter $\left(C_{\mathrm{in}}\right)$, coupled inductor of the primary side $\left(L_{1}\right)$, and an IGBT as a switching device $\left(Z_{1}\right)$ with a diode $\left(D_{Z 1}\right)$. The secondary side circuit consists of the following components: coupled inductor of the secondary side $\left(L_{2}\right)$, connecting capacitor $\left(C_{3}\right)$, rectifier diode $\left(D_{4}\right)$, and rectifier output diode $\left(D_{o}\right)$. There are two parts in the snubber circuit, namely, the active regenerative snubber circuit (part 4a) and the passive regenerative snubber circuit (part $4 \mathrm{~b}$ ). The components of the active regenerative snubber circuit are as follows: IGBT as a switching device $\left(Z_{2}\right)$ with a diode $\left(D_{Z 2}\right)$, input capacitor $\left(C_{1}\right)$, output capacitor $\left(C_{2}\right)$, input diode $\left(D_{1}\right)$ for input capacitor $\left(C_{1}\right)$, input diode $\left(D_{2}\right)$ for switching device $\left(Z_{2}\right)$, snubber inductor $\left(L_{S}\right)$, and rectifier diode $\left(D_{3}\right)$. The passive regenerative snubber circuit has the following components: diodes $\left(D_{5}\right.$ and $\left.D_{6}\right)$ and snubber capacitor $\left(C_{s}\right)$. The output filter and output side are represented by the following components: filter capacitor $\left(C_{o}\right)$ with output or load voltage $\left(V_{o}\right)$ and output or load current $\left(I_{o}\right)$.

Based on the circuit and detailed mathematical analyses in [16], the voltage gain $\left(G_{i}\right)$ of the high-performance boost converter is given as following equation:

$$
G_{i}=\frac{V_{o}}{V_{\text {in }}}=n k+\frac{1+d \cdot n \cdot k}{1-d}+\frac{1}{(1-d)^{2}},
$$


TABLE 2: Boost converter circuit components values.

\begin{tabular}{lll}
\hline Symbol & Name & Value \\
\hline$Z_{1}$ with $D_{Z 1}$ and $Z_{2}$ with $D_{Z 2}$ & $\begin{array}{l}\text { IGBT with antiparallel diode, and first } \\
\text { and second components }\end{array}$ & Rating $1200 \mathrm{~V}, 30 \mathrm{~A}$ \\
$D_{1}, D_{2}, D_{3}, D_{4}, D_{5}, D_{6}$, and $D_{o}$ & $\begin{array}{l}\text { Fast recovery diode, and first to sixth } \\
\text { output components }\end{array}$ & Rating $1200 \mathrm{~V}, 15 \mathrm{~A}$ \\
$L_{1}-L_{2}$ & Coupled inductor & $1 \mathrm{mH}-1 \mathrm{mH}$, rating $30 \mathrm{~A}$ \\
$L_{S}$ & Inductor & $1 \mathrm{mH}$, rating $30 \mathrm{~A}$ \\
$C_{1}, C_{2}$, and $C_{S}$ & Snubber capacitors, and first and second & Capacitance $0.47 \mu \mathrm{F}, 0.01 \mu \mathrm{F}$, and $0.01 \mu \mathrm{F}$, \\
$C_{3}$ & and $s$ snubber components & respectively rating $1000 \mathrm{~V}$ \\
$C_{\text {in }}$ and $C_{o}$ & AC capacitor & $6.8 \mu \mathrm{F}$, rating $1000 \mathrm{~V}$ \\
\hline
\end{tabular}

TABLE 3: Performance comparison of the experimental output voltages of the various proposed and conventional boost converters.

\begin{tabular}{|c|c|c|c|c|c|c|c|}
\hline \multirow{3}{*}{ Input voltage $(\mathrm{V})$} & \multirow{3}{*}{ Duty cycle } & \multicolumn{6}{|c|}{ Boost converter topology } \\
\hline & & \multicolumn{3}{|c|}{ Conventional } & \multicolumn{3}{|c|}{ Proposed } \\
\hline & & $\begin{array}{l}\text { Input current } \\
\text { (A) }\end{array}$ & $\begin{array}{l}\text { Output current } \\
\text { (A) }\end{array}$ & $\begin{array}{c}\text { Output voltage } \\
\text { (V) }\end{array}$ & $\begin{array}{c}\text { Input current } \\
\text { (A) }\end{array}$ & $\begin{array}{l}\text { Output current } \\
\text { (A) }\end{array}$ & $\begin{array}{c}\text { Output voltage } \\
(\mathrm{V})\end{array}$ \\
\hline \multirow{3}{*}{30} & 0.2 & 0.4 & 0.21 & 40 & 2.58 & 0.54 & 116 \\
\hline & 0.3 & 0.51 & 0.25 & 45 & 3.73 & 0.67 & 140 \\
\hline & 0.4 & 0.69 & 0.3 & 53 & 6.72 & 0.85 & 200 \\
\hline \multirow{3}{*}{50} & 0.2 & 0.73 & 0.42 & 67 & 4.56 & 0.9 & 218 \\
\hline & 0.3 & 0.9 & 0.47 & 74 & 6.81 & 1.15 & 261 \\
\hline & 0.4 & 1.17 & 0.53 & 86 & 11.02 & 1.5 & 327 \\
\hline \multirow{3}{*}{100} & 0.2 & 1.2 & 0.69 & 136 & 8.65 & 1.86 & 415 \\
\hline & 0.3 & 1.45 & 0.74 & 155 & 13.03 & 2.3 & 510 \\
\hline & 0.4 & 1.87 & 0.83 & 182 & 21.24 & 2.96 & 646 \\
\hline \multirow{3}{*}{200} & 0.2 & 2.14 & 1.27 & 273 & 18.3 & 4.13 & 798 \\
\hline & 0.3 & 2.73 & 1.43 & 310 & 23.61 & 4.39 & 936 \\
\hline & 0.4 & 3.71 & 1.68 & 361 & 30.16 & 4.82 & 1072 \\
\hline
\end{tabular}

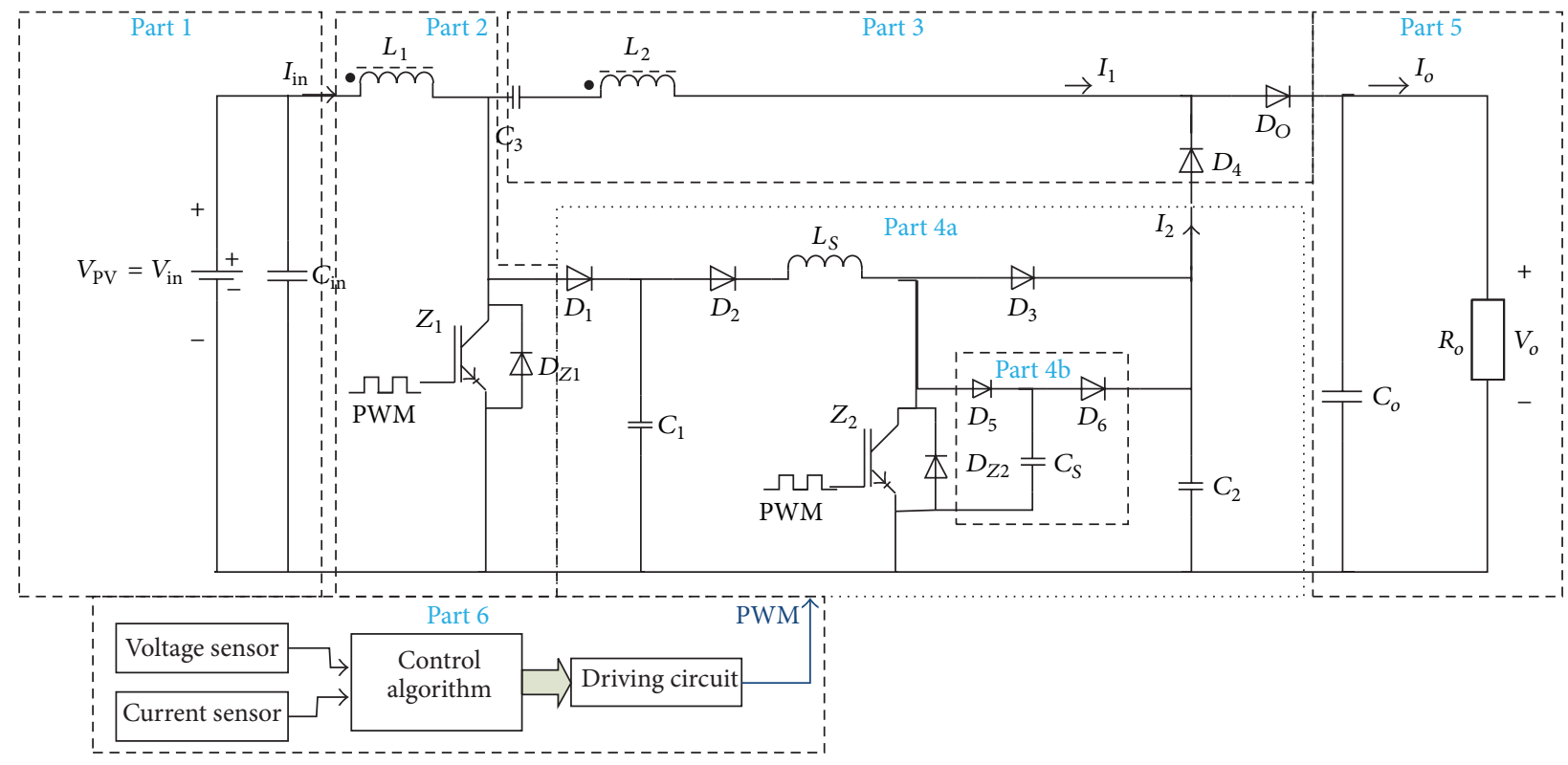

FIGURE 2: Schematic circuit of the high-performance boost converter. 


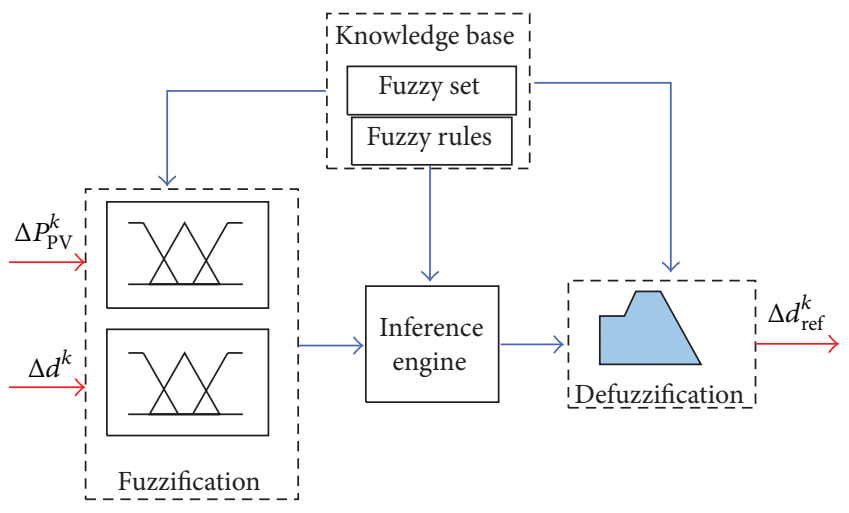

FIGURE 3: Structure of a two input-one output FLC for MPPT application.

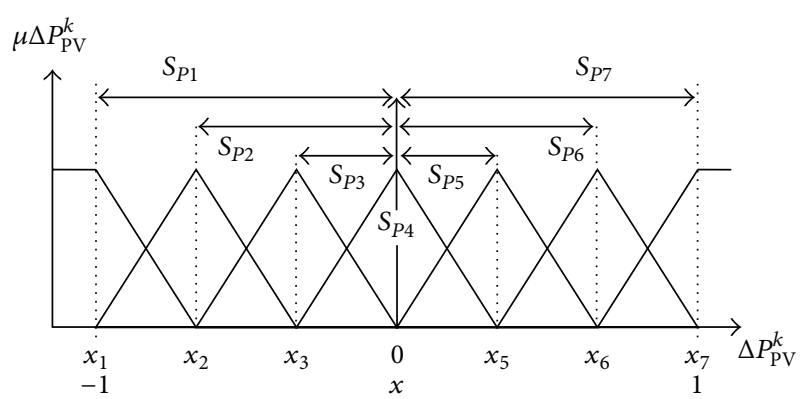

FIGURE 4: Mapping neurons on the membership functions coding for $\Delta P_{\mathrm{PV}}$.

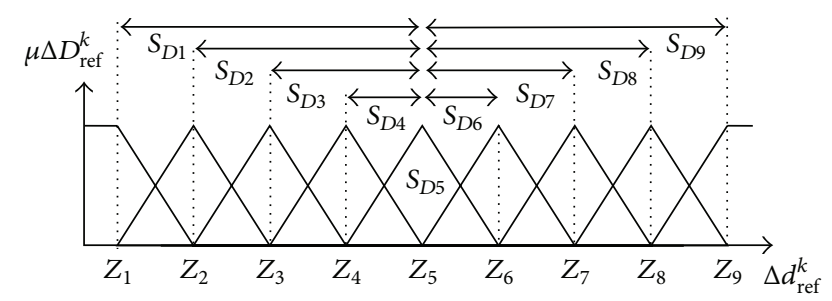

FIGURE 5: Mapping neurons on the membership functions coding for $\Delta d_{\text {ref }}$.

where $n$ is the turn ratio of the coupled inductor that can be regarded as an ideal transformer, $k$ is the coupling coefficient $(0 \leq k \leq 1)$, and $d$ is the duty cycle of the triggering switching signal $\left(d=t_{\text {on }} / t_{\text {off }}\right)$.

Equation (1) reveals that the voltage gain of the proposed boost converter is much greater than the voltage gain of the conventional boost converter and higher than the previously reported coupled inductor-based boost converters [15, 17].

\section{MPPT Control Algorithm Using FLC and HNN}

3.1. Fuzzy Logic Controller (FLC) for MPPT of PV Systems. A typical FLC includes three major parts: the fuzzification module at the input terminal, the inference engine in the core, and the defuzzification module at the output terminal. The

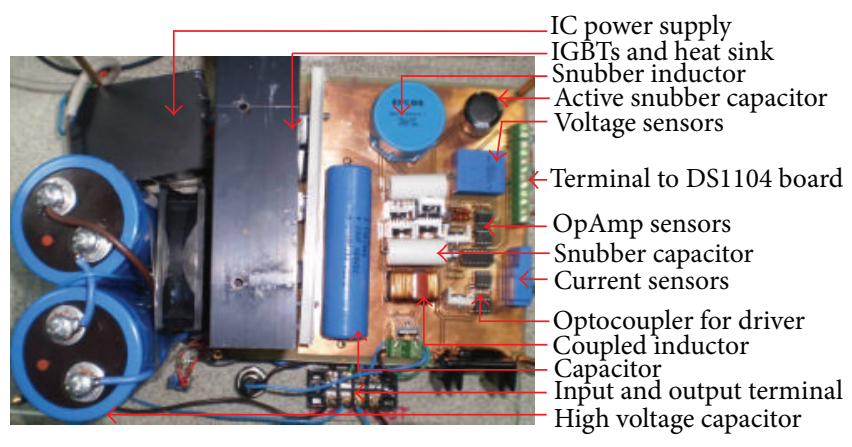

FIGURE 6: Prototype boost converter circuit implemented on the PCB.

basic structure of an FLC is shown in Figure 3. In this case, there are two input signals, that is, the change in PV power $\left(\Delta P_{\mathrm{PV}}^{k}\right)$ and change in direction of duty cycle $\left(\Delta d^{k}\right)$, and one output signal, which is the duty cycle that must be applied to control DC-DC converter switching $\left(\Delta d_{\text {ref }}^{k}\right)$ such that all signals are crisp values.

The universe of discourse for the first input variable $\left(\Delta P_{\mathrm{PV}}^{k}\right)$ is assigned in terms of its linguistic variable using seven fuzzy subsets denoted by negative large (NL), negative medium (NM), negative small (NS), zero $(Z)$, positive small (PS), positive medium (PM), and positive large (PL). The universe of discourse for the second input variable $\left(\Delta d^{k}\right)$ is classified into three fuzzy sets, namely, negative $(N)$, zero $(Z)$, and positive $(P)$. The output variable $\left(\Delta d_{\mathrm{ref}}^{k}\right)$ is assigned in terms of its linguistic variable using nine fuzzy subsets denoted by negative double large $(\mathrm{NL}) \mathrm{L}$, negative large (NL), negative medium (NM), negative small (NS), zero $(Z)$, positive small (PS), positive medium (PM), positive large (PL), and positive double large (PLL).

The fuzzy rules are generated as shown in Table 1 with $\Delta P_{\mathrm{PV}}^{k}$ and $\Delta d^{k}$ as inputs and $\Delta d_{\mathrm{ref}}^{k}$ as the output. This table is also known as the fuzzy associative matrix. The fuzzy inference of the FLC is based on Mamdani's method, which is associated with the max-min composition. The defuzzification technique is based on the centroid method, which is used to compute the crisp output, $\Delta d_{\text {ref. }}^{k}$.

3.2. Optimized FLC Using the HNN for MPPT of PV Systems. The HNN is useful for associative memory and optimization in a symmetrical structure [18]. The HNN uses a two-state threshold "neuron" that follows a stochastic algorithm where each neuron or processing element, $N_{i}$, has two states, with values of either zerp or one in discrete, and between zero until one in continuous application. The inputs of each neuron come from two sources, namely, external inputs $\left(I_{i}\right)$ and inputs from other neurons $\left(N_{j}\right)$. The total input to neuron $N_{i}$ is given by

$$
u_{i}=I_{i}+\sum_{j} w_{i j} \cdot o_{-} N_{j},
$$




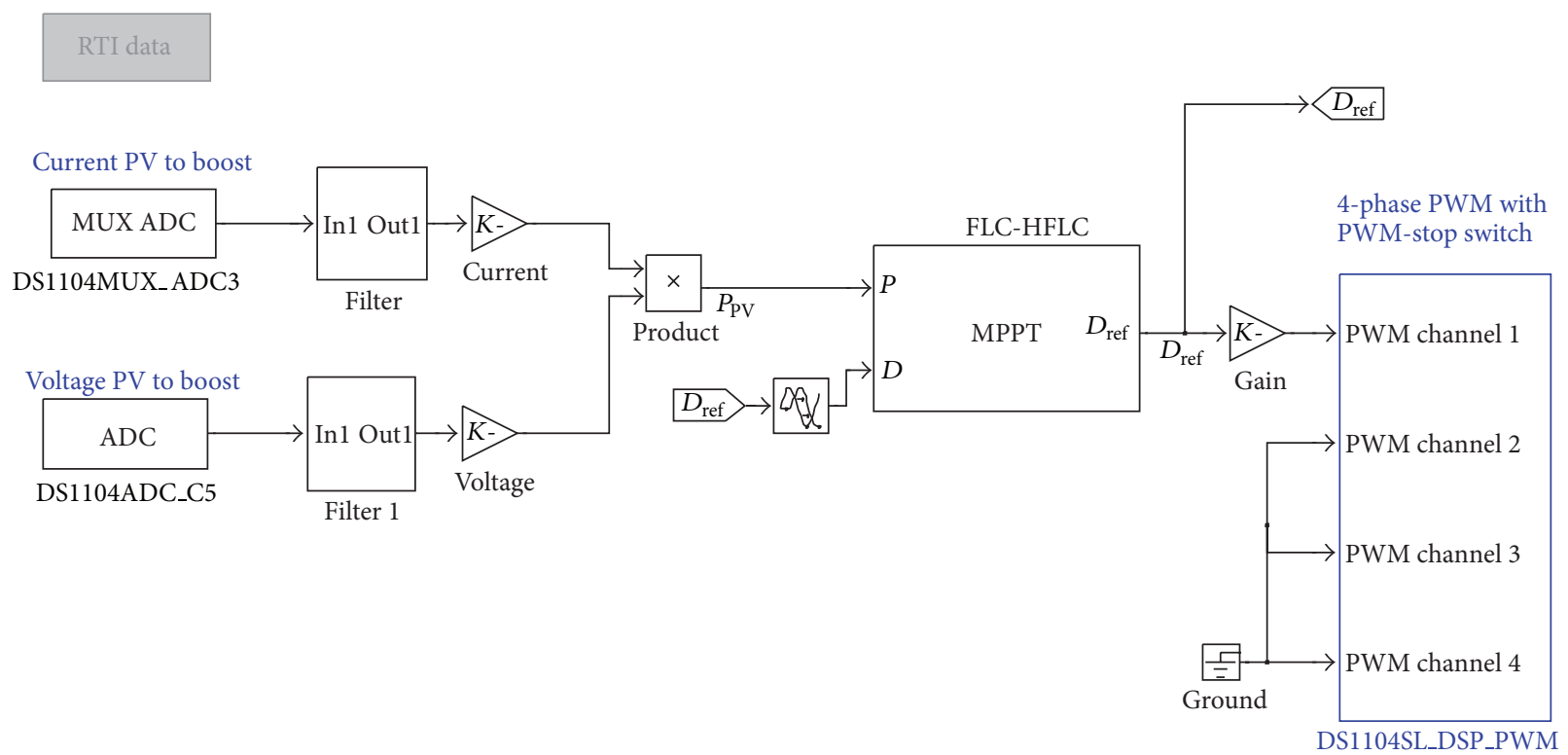

FIGURE 7: Control system model using the RTI library for PWM signal generation.

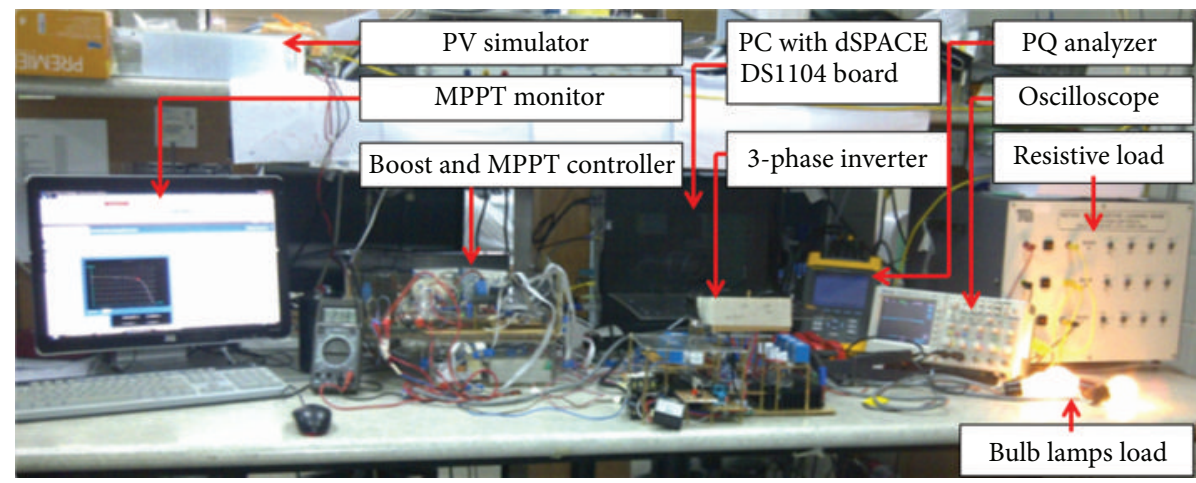

FIGURE 8: Laboratory experimental setup for testing the MPPT controller using the agilent PV simulator.

where $u_{i}$ is the input of HNN, $w_{i j}$ is the synaptic interconnection strength from neuron $N_{i}$ to neuron $N_{j}, I_{i}$ is the external input to neuron $N_{i}$, and $o_{-} N_{j}$ is the output of neuron $N_{j}$.

A typical output of neuron $N_{i}$ is a sigmoid function. Mathematically, it is given by [19]

$$
o \_N_{i}=g\left(\lambda u_{i}\right)=\frac{1}{1+e^{-\lambda u_{i}}},
$$

where $\lambda$ is the gain that determines the shape of the sigmoid function.

The energy function $E$ of the continuous $\mathrm{HNN}$ is similarly defined as [19]

$$
E=-\left[\frac{1}{2} \sum_{i=1}^{n} \sum_{j=1}^{n} w_{i j} O \_N_{i} \cdot o_{-} N_{j}+\sum_{i=1}^{n} I_{i} o_{-} N_{i}\right]
$$

and its change in energy is given by

$$
\Delta E=-\left[\sum_{j} o_{-} N_{j} \cdot w_{i j}+I_{i}\right] \Delta o_{-} N_{i}
$$

The change in energy is always less than zero because $g$ is a monotonically increasing function. Therefore, the network solution moves in the same direction as the decrease in energy. The solution seeks out a minimum of $E$ and comes to a stop at the stability point.

In the design of the proposed optimal FLC, two inputs, $\Delta P_{\mathrm{PV}}^{k}$ and direction $\Delta d^{k}$, and one output, $\Delta d_{\text {ref }}^{k}$, are used as described before. For simplicity, the design is only based on membership functions of $\Delta P_{\mathrm{PV}}^{k}$ and $\Delta d_{\mathrm{ref},}^{k} \cdot \Delta P_{\mathrm{PV}}^{k}$ is described by seven membership functions, as illustrated in Figure 4, and $\Delta d_{\text {ref }}^{k}$ is described by nine membership functions, as illustrated in Figure 5. In Figure 4, the centers of the $\Delta P_{\mathrm{PV}}^{k}$ membership function are $x_{1}, x_{2}, x_{3}, x_{4}, x_{5}, x_{6}$, and $x_{7}$. In Figure 5 , the centers of $\Delta d_{\text {ref }}^{k}$, membership functions are $z_{1}, z_{2}, z_{3}, z_{4}$, $z_{5}, z_{6}, z_{7}, z_{8}$, and $z_{9}$. Based on the number of centers of $\Delta P_{\mathrm{PV}}^{k}$ and $\Delta d_{\text {ref }}^{k}$, the proposed HNN consists of 16 neurons with variables given as $x_{1}=-S_{P 1}, x_{2}=-S_{P 2}, x_{3}=-S_{P 3}, x_{4}=$ $S_{P 4}, x_{5}=S_{P 5}, x_{6}=S_{P 6}, x_{7}=S_{P 7}, z_{1}=-S_{D 1}, z_{2}=$ $-S_{D 2}, z_{3}=-S_{D 3}, z_{4}=-S_{D 4}, Z_{5}=S_{D 5}, Z_{6}=S_{D 6}, Z_{7}=S_{D 7}$, 
$Z_{8}=S_{D 8}$, and $Z_{9}=S_{D 9} . S_{P 1}$ until $S_{P 7}$ are output values of neurons $N_{1}$ until $N_{7}\left(o \_N_{1}-o \_N_{7}\right)$, whereas $S_{D 1}$ until $S_{D 9}$ are output values of neurons $N_{8}$ until $N_{16}\left(o_{-} N_{8}-o_{-} N_{16}\right)$.

When calculating the values of neurons in Figures 4 and 5 , the following constraints should be satisfied:

$$
\begin{gathered}
S_{P 4}=0, \\
S_{P 1}=\text { SPmax_left, } \\
S_{P 7}=\text { SPmax_right, } \\
0 \leq S_{P 3} \leq S_{P 2} \leq S_{P 1}, \\
0 \leq S_{P 6} \leq S_{P 5} \leq S_{P 7}, \\
S_{D 5}=0, \\
S_{D 1}=\text { SDmax_left, } \\
S_{D 9}=\text { SDmax_right, } \\
0 \leq S_{D 4} \leq S_{D 3} \leq S_{D 2} \leq S_{D 1}, \\
0 \leq S_{D 6} \leq S_{D 7} \leq S_{D 8} \leq S_{D 9} .
\end{gathered}
$$

According to the implementation of FLC for MPPT, the control system converges at $\Delta P_{\mathrm{PV}}^{k}=0$ and $\Delta d_{\text {ref }}^{k}=0$. The goal of MPPT is to achieve $\Delta P_{\mathrm{PV}}^{k}=0$ and $\Delta d_{\mathrm{ref}}^{k},=0$. Therefore, the objective function is assumed by minimizing

$$
E=E_{1}+E_{2}=\frac{1}{2} A\left(\Delta P_{\mathrm{PV}}^{k}\right)^{2}+\frac{1}{2} B\left(\Delta d_{\mathrm{ref}}^{k}\right)^{2},
$$

where $E$ is the energy function to be minimized and $A$ and $B$ are constants.

From (7), the first part of $E$, which is $E_{1}$, only depends on the universe of $\Delta P_{\mathrm{PV}}^{k}$, which is the first input of FLC. $\Delta P_{\mathrm{PV}}^{k}$ is defined by the defuzzification of the universe of $\Delta P_{\mathrm{PV}}^{k}$ using a centroid function [20], which is written as

$$
\Delta P_{\mathrm{PV}}^{k}=\frac{\sum_{i=1}^{7} \mu\left(\Delta P_{\mathrm{PV}}^{k}\right)_{i} x_{i}}{\sum_{i=1}^{7} \mu\left(\Delta P_{\mathrm{PV}}^{k}\right)_{i}},
$$

where $\mu\left(\Delta P_{\mathrm{PV}}^{k}\right)_{i}$ is the membership value of $x_{i}$.

$E_{1}$ depends only on neurons $N_{i}(i=1,2,3,4,5,6,7)$. Knowing that the left side of $\Delta P_{\mathrm{PV}}^{k}$ in the membership function of the first input is $\mu\left(\Delta P_{\mathrm{PV}}^{k}\right)_{i} \neq 0$ for $x_{1}, x_{2}$, and $x_{3}$, then solving $E_{1}$ yields

$$
\begin{gathered}
E_{1}=\frac{1}{2}\left(\sum_{i=4}^{7} \sum_{j=4}^{7}\left(\frac{A \mu\left(\Delta P_{\mathrm{PV}}^{k}\right)_{i} \mu\left(\Delta P_{\mathrm{PV}}^{k}\right)_{j}}{\sum_{i=1}^{7} \sum_{j=1}^{7} \mu\left(\Delta P_{\mathrm{PV}}^{k}\right)_{i} \mu\left(\Delta P_{\mathrm{PV}}^{k}\right)_{j}}\right)\right. \\
\left.\times o \_N_{i} \cdot o \_N_{j}\right) .
\end{gathered}
$$

The second part of $E$ in (7) is related to the output of FLC and depends only on neurons $N_{i}(i=8,9,10,11$,
$12,13,14,15$, and 16). $\Delta d_{\text {ref }}^{k}$ can be defined by defuzzification using the centroid method and $E_{2}$ can be obtained as

$$
\begin{aligned}
E_{2}=\frac{1}{2}\left(\sum_{i=8}^{16} \sum_{j=8}^{16}\left(\frac{B \mu\left(\Delta d_{\mathrm{PV}}^{k}\right)_{i} \mu\left(\Delta d_{\mathrm{PV}}^{k}\right)_{j}}{\sum_{i=8}^{16} \sum_{j=8}^{16} \mu\left(\Delta d_{\mathrm{PV}}^{k}\right)_{i} \mu\left(\Delta d_{\mathrm{PV}}^{k}\right)_{j}}\right)\right. \\
\left.\times o \_N_{i} \cdot o \_N_{j}\right),
\end{aligned}
$$

where $N=0$ for $i=12$ and $j=12$, and $\mu\left(\Delta d_{\text {ref }}^{k}\right)$ is the membership value of $z_{n}$. Finally, the total energy function $E=$ $E_{1}+E_{2}$ defined in (7) becomes

$$
\begin{aligned}
E=\frac{1}{2}\left(\sum_{i=1}^{7} \sum_{j=1}^{7}\left(\frac{A \mu\left(\Delta P_{\mathrm{PV}}^{k}\right)_{i} \mu\left(\Delta P_{\mathrm{PV}}^{k}\right)_{j}}{\sum_{i=1}^{7} \sum_{j=1}^{7} \mu\left(\Delta P_{\mathrm{PV}}^{k}\right)_{i} \mu\left(\Delta P_{\mathrm{PV}}^{k}\right)_{j}}\right)\right. \\
\left.\times o_{-} N_{i} \cdot o_{-} N_{j}\right) \\
+\frac{1}{2}\left(\sum_{i=8}^{16} \sum_{j=8}^{16}\left(\frac{B \mu\left(\Delta d_{\mathrm{ref}}^{k}\right)_{i} \mu\left(\Delta d_{\mathrm{ref}}^{k}\right)_{j}}{\sum_{i=8}^{16} \sum_{j=8}^{16} \mu\left(\Delta d_{\mathrm{ref}}^{k}\right)_{j} \mu\left(\Delta d_{\mathrm{ref}}^{k}\right)_{j}}\right)\right. \\
\left.\times o \_N_{i} \cdot o \_N_{j}\right),
\end{aligned}
$$

where $N=0$ for $i=4,12$ and $j=4,12$.

Comparing (4) with (11), the weight matrix of neurons $N_{i}$ to $N_{j}$ in the HNN is derived and given as

$$
w_{i j}=\left[\begin{array}{ccccc}
w_{11} & w_{12} & w_{13} & \cdots & 0 \\
w_{21} & w_{22} & & & \\
w_{31} & w_{32} & & & \\
\vdots & & & & \\
0 & 0 & 0 & & w_{n n}
\end{array}\right],
$$

where

$$
\begin{gathered}
w_{i j}=-\frac{A \mu\left(\Delta P_{\mathrm{PV}}^{k}\right)_{i} \mu\left(\Delta P_{\mathrm{PV}}^{k}\right)_{j}}{\sum_{i=1}^{7} \sum_{j=1}^{7} \mu\left(\Delta P_{\mathrm{PV}}^{k}\right)_{i} \mu\left(\Delta P_{\mathrm{PV}}^{k}\right)_{j}}, \\
\text { for } i \text { and } j=1,2,3,4,5,6,7 \\
w_{i j}=-\frac{B \mu\left(\Delta d_{\mathrm{ref}}^{k}\right)_{i} \varphi \mu\left(\Delta d_{\mathrm{ref}}^{k}\right)_{j}}{\sum_{i=8}^{16} \sum_{j=8}^{16} \mu\left(\Delta d_{\mathrm{ref}}^{k}\right)_{i} \mu\left(\Delta_{\mathrm{ref}}^{k}\right)_{j}}, \\
\text { for } i \text { and } j=8,9,10,11,12,13,14,15,16 \\
w_{i j}=0 \quad \text { for other. }
\end{gathered}
$$

\section{Hardware Implementation}

Figure 6 shows a photograph of the prototype of the proposed boost converter circuit implemented on the PCB. 


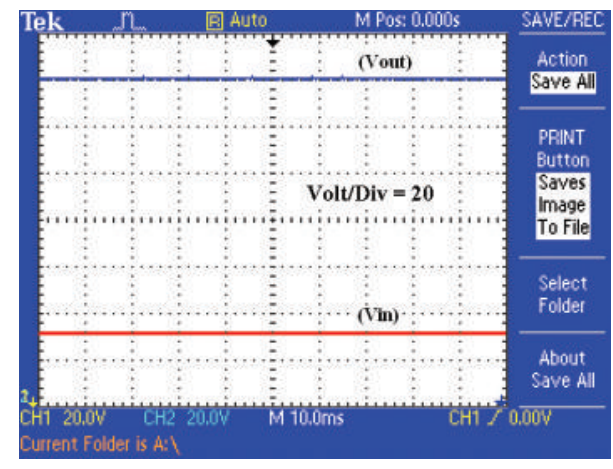

(a)

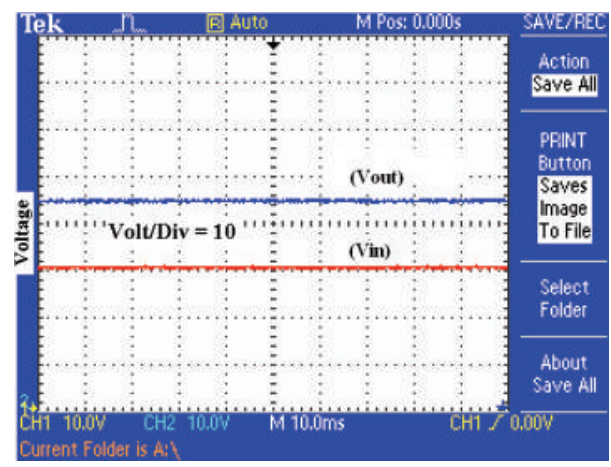

(b)

FIGURE 9: Output voltages obtained experimentally: (a) proposed boost converter and (b) conventional boost converter.

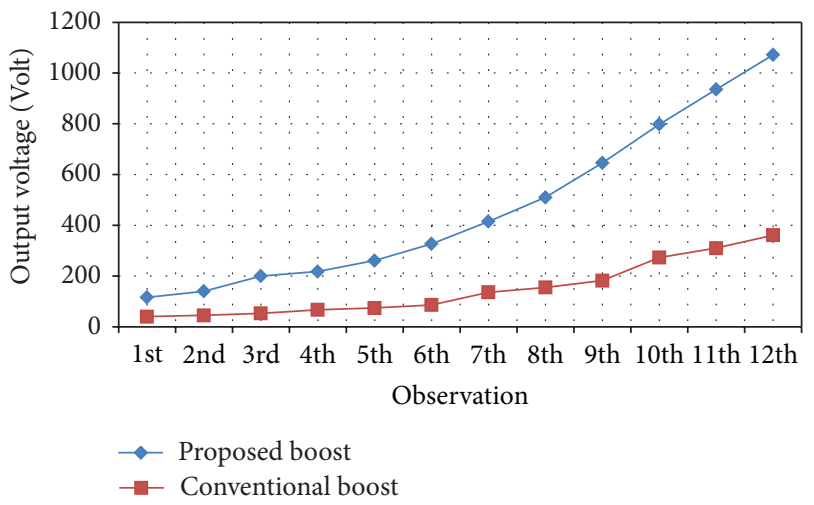

FIGURE 10: Proposed and conventional boost converter output voltages.

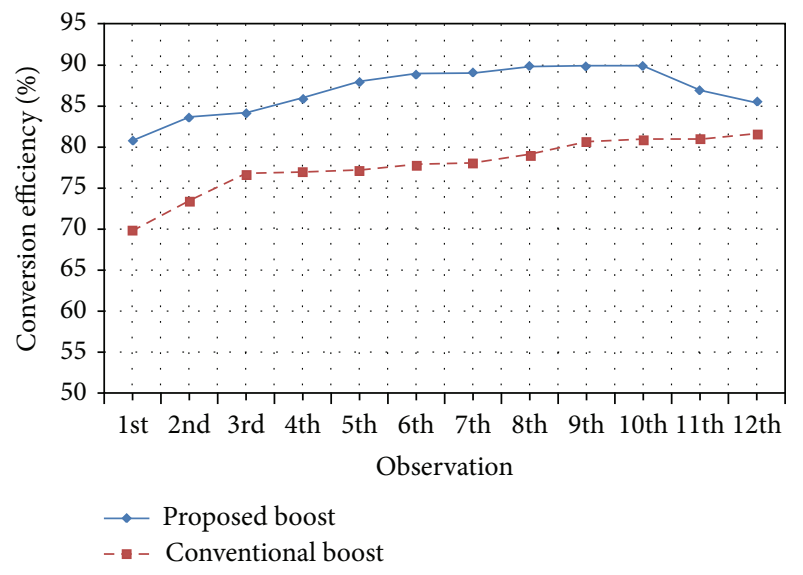

FIGURE 11: Proposed and conventional boost converter efficiencies.

The proposed boost converter is designed to provide 700-900 $V_{\mathrm{dc}}$ for the input requirement of the three-phase inverter of $3 \mathrm{~kW}$ rating. Therefore, the IGBTs as switching devices with protection diodes $D_{Z}$ and $D_{1}, D_{2}, D_{3}, D_{4}, D_{5}, D_{6}$, and $D_{o}$ are limited to an output voltage of $1000 \mathrm{~V}$. The capacitors selected are able to withstand $1000 \mathrm{~V}$. The connecting capacitor $C_{3}$ is selected as a high AC voltage capacitor at the secondary side. Based on the mathematical analysis and all the above considerations, the various components and devices in the proposed boost converter circuit are calculated at a switching frequency of $50 \mathrm{kHz}$ as shown in Table 2 .

For the implementation of the MPPT algorithm in dSPACE, the control design for the dSPACE real-time interrupt (RTI) control system method is constructed based on the Simulink model. Figure 7 shows the implementation of the MPPT algorithm using the RTI library in the form of a block diagram model. The MPPT block model is embedded with the $\mathrm{C}$ codes for implementing the MPPT algorithms using the Hopfield FLC (HFLC) technique. The MUXADC and ADC blocks read the current and voltage sensor signals, respectively. The PWM signal is generated by the DS1104 SL_DSP_PWM block. The signal is transferred to I/O pin number 21 of the P1B sub-D connector. The RTI control system is downloaded to the DS1104 board to generate PWM to trigger the IGBTs on the prototype.

The MPPT controller prototype is tested using a $1 \mathrm{~kW}$ Agilent E4360 A PV solar array simulator (SAS), as shown in Figure 8. It is also connected to a $3 \mathrm{~kW}$ PV panel consisting of 25 PV modules of the SolarTIF STF-120P6PV type.

\section{Experimental Results}

The performance verification of the new boost converter and intelligent MPPT controller for a PV system are discussed in the following experimental results.

5.1. High-Performance Boost Converter. To evaluate the performance of the new boost converter, the effect of the duty cycle on the boost converter output voltage is investigated. The result is compared with that of the conventional boost converter topology. Figure 9 depicts the output voltages obtained from the proposed and conventional boost converters. The output voltages of the proposed boost converter $(140 \mathrm{~V})$ are approximately three times greater than those of the conventional boost converter $(45 \mathrm{~V})$. The effects of duty cycle and various input voltages on the output voltages of both proposed and conventional boost converters are presented in Table 3. Figure 10 compares the output voltages of the new 


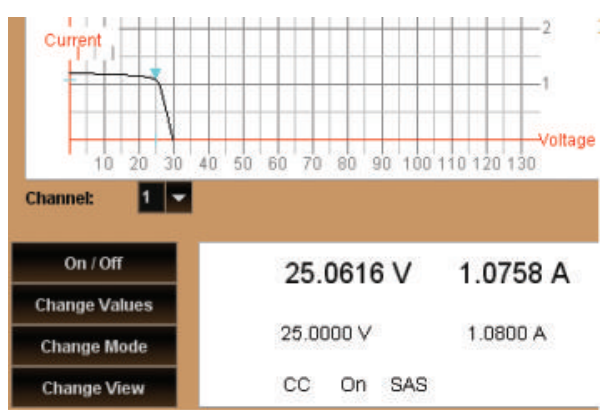

(a)

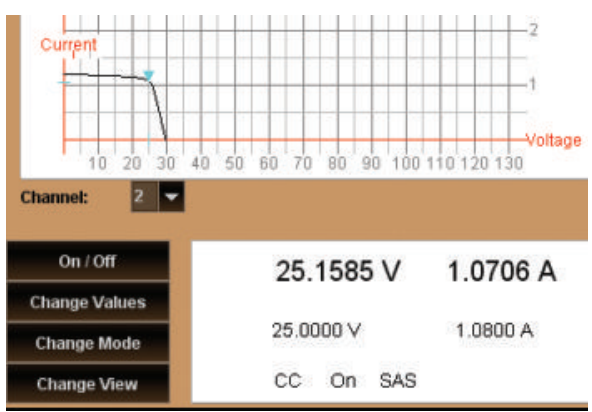

(b)

FIGURE 12: Experimental result of the MPPT controller at (a) channel 1 and (b) channel 2 of the agilent SAS simulator for 54 W power tracking.

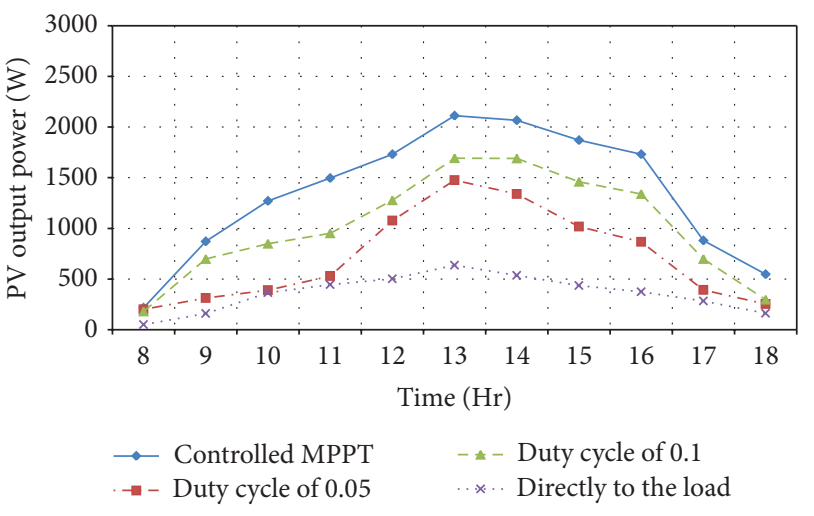

(a)

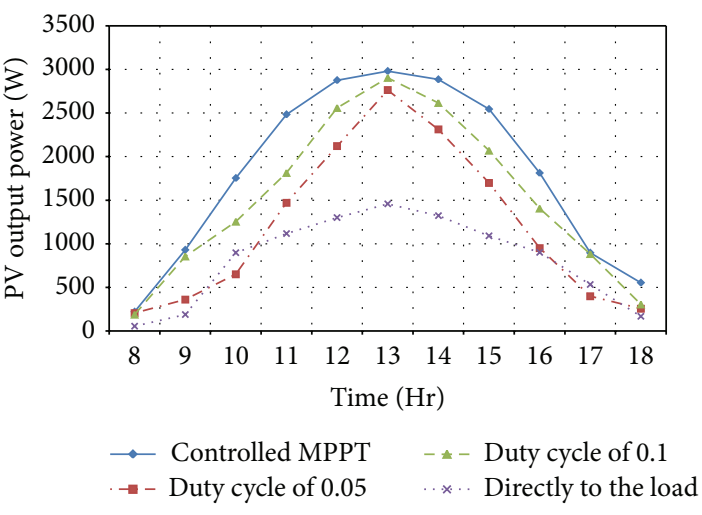

(b)

FIgURE 13: Comparison hourly PV powers with and without MPPT controller on samples (a) 1 and (b) 2.

and conventional boost converters. The former gives a voltage gain much higher than the latter.

From the currents and voltages shown in Table 3, the input and output powers, as well as the efficiency of the proposed and conventional boost converters are calculated. Figure 11 shows the plot of the efficiencies of the proposed and conventional boost converters against the input power. The maximum efficiency of the proposed boost converter is $90 \%$ at an input power of $3.6 \mathrm{~kW}$. The proposed boost converter is able to enhance the efficiency of the conventional boost converter by approximately $9 \%$.

5.2. Experimental Testing of the MPPT Controller. To assess the performance of the prototype MPPT controller, initial experiments were conducted using an agilent PV SAS simulator at $54 \mathrm{~W}, 200 \mathrm{~W}$, and $848.6 \mathrm{~W}$ of power. The results of testing the MPPT controller for tracking the $54 \mathrm{~W}$ power from the PV simulator are captured in terms of the voltagecurrent $(V-I)$ curve and PV MPP, as shown in Figures 12(a) and 12(b) for channels 1 and 2, respectively. The theoretical MPP is 25.0 and $1.08 \mathrm{~A}$. The results of the MPP and $V-I$ curve of the PV array channel 1 as shown in Figure 12(a) indicate that the MPP is at a voltage of $25.0616 \mathrm{~V}$ and a current of $1.0758 \mathrm{~A}$. However, the results of the MPP and $V-I$ curve of the PV array channel 2 shown in Figure 12(b) indicate that the MPP is at $25.1585 \mathrm{~V}$ and $1.0706 \mathrm{~A}$. Given that the MPP experimental results are close to the theoretical MPP (with an error of $0.19 \%$ ), the prototype MPPT controller is considered to give the accurate MPPT of the PV system. The slight differences in the MPP results at channels 1 and 2 may be have been caused by oscillation at around the MPP.

The prototype MPPT controller is also tested by connecting it to a $3 \mathrm{kWPV}$ array and a resistive load of $210 \Omega$. The boost converter was tested by the controlled PWM with and without MPPT, that is, using triggering signals at duty cycles of 0.05 and 0.1 . For further comparison, testing was done by directly connecting the PV panel to the load. From the measured current and voltage values, the PV output powers are calculated and plotted versus time, as shown in Figure 13. The maximum power can be obtained from the PV array using the HFLC-based MPPT controller compared with using only the constant duty cycle boost converter and without the MPPT controller. The prototype MPPT controller can also efficiently track the maximum power from the PV array, drawing 2.11 and $2.98 \mathrm{~kW}$ power from the rated $3 \mathrm{~kW} \mathrm{PV}$ array for samples 1 and 2, respectively. If the PV array is directly connected to a resistive load bank without installing the MPPT controller, only 0.65 and $1.46 \mathrm{~kW}$ powers are drawn for samples 1 and 2 , respectively. Hence, the prototype MPPT controller can produce 2.4 times more PV power than that without using the MPPT controller. 
The results prove the effectiveness of using the MPPT controller in PV system operation so that the maximum PV output power can be obtained.

\section{Conclusion}

This paper has presented a new MPPT controller for PV generation systems using an improved boost converter design and a novel MPPT algorithm. This novel MPPT algorithm based on the HFLC is developed for extracting the PV array power at its maximum. A hardware prototype of the proposed boost converter is developed and tested for verification. The proposed boost converter gives better energy conversion efficiency (90\%) than conventional boost converters (81\%). Laboratory testing of the MPPT controller is implemented using a $1 \mathrm{~kW}$ agilent PV solar array simulator. For the actual field testing of the MPPT controller, it is connected to a $3 \mathrm{~kW}$ SolarTIF STF-120P6PV PV array.

\section{References}

[1] T. J. Hammons, J. C. Boyer, S. R. Conners et al., "Renewable energy alternatives for developed countries," IEEE Transactions on Energy Conversion, vol. 15, no. 4, pp. 481-493, 2000.

[2] O. Gil-Arias and E. I. Ortiz-Rivera, "A general purpose tool for simulating the behavior of PV solar cells, modules and arrays," in Proceedings of the 11th IEEE Workshop on Control and Modeling for Power Electronics (COMPEL '08), pp. 1-5, August 2008.

[3] F. Dinçer and M. E. Meral, "Critical factors that affecting efficiency of solar cells," Smart Grid and Renewable Energy, vol. 1, pp. 47-50, 2010.

[4] V. Salas, E. Olías, A. Barrado, and A. Lázaro, "Review of the maximum power point tracking algorithms for stand-alone photovoltaic systems," Solar Energy Materials \& Solar Cells, vol. 90, pp. 1555-1578, 2006.

[5] J. A. R. Hernanz, J. J. C. Martín, I. Z. Belver, J. L. Lesaka, E. Z. Guerrero, and E. P. Pérez, "Modelling of photovoltaic module," in Proceedings of the International Conference on Renewable Energies and Power Quality (ICREPQ '10), pp. 1-5, Granada, 2010.

[6] T. Esram and P. L. Chapman, "Comparison of photovoltaic array maximum power point tracking techniques," IEEE Transactions on Energy Conversion, vol. 22, no. 2, pp. 439-449, 2007.

[7] M. M. Algazara, H. Al-monierb, H. Abd El-halima, and M. E. El Kotb Salem, "Maximum power point tracking using fuzzy logic control," International Journal of Electrical Power \& Energy Systems, vol. 39, no. 1, pp. 21-28, 2012.

[8] R. Balaji, M. Ramaprabha, and B. L. Mathur, "Maximum power point tracking of partially shaded solar PV system using modified Fibonacci search method with fuzzy controller," International Journal of Electrical Power \& Energy Systems, vol. 43, no. 1, pp. 754-765, 2012.

[9] N. Patcharaprakiti and S. Premrudeepreechacharn, "Maximum power point tracking using adaptive fuzzy logic control for grid-connected photovoltaic system," in Proceedings of the IEEE Power Engineering Society Winter Meeting, vol. 1, pp. 372-377, January 2002.

[10] A. Messai, A. Mellit, A. Guessoum, and S. A. Kalogirou, "Maximum power point tracking using a GA optimized fuzzy logic controller and its FPGA implementation," Solar Energy, vol. 85 , no. 2, pp. 265-277, 2011.

[11] N. Khaehintung, A. Kunakorn, and P. Sirisuk, "A novel fuzzy logic control technique tuned by particle swarm optimization for maximum power point tracking for a photovoltaic system using a current-mode boost converter with bifurcation control," International Journal of Control, Automation and Systems, vol. 8, no. 2, pp. 289-300, 2010.

[12] H. Su and J. Bian, "Maximum power point tracking algorithm based on fuzzy Neural Networks for photovoltaic generation system," in Proceedings of the International Conference on Computer Application and System Modeling (ICCASM '10), vol. 1, pp. 353-357, October 2010.

[13] M. K. Kazimierczuk, Pulse-Width Modulated DC-DC Power Converters, John Wiley and Sons, Singapore, 1st edition, 2008.

[14] R. J. Wai, W. H. Wang, and C. Y. Lin, "High-performance standalone photovoltaic generation system," IEEE Transactions on Industrial Electronics, vol. 55, no. 1, pp. 240-250, 2008.

[15] R. J. Wai and W. H. Wang, "Grid-connected photovoltaic generation system," IEEE Transactions on Circuits and Systems I, vol. 55, no. 3, pp. 953-964, 2008.

[16] Subiyanto, A. Mohamed, and M. A. Hannan, "Photovoltaic maximum power point tracking controller using a new high performance boost converter," International Review of Electrical Engineering, vol. 5, no. 6, pp. 2535-2545, 2010.

[17] Q. Zhao and F. C. Lee, "High-efficiency, high step-up dc-dc converters," IEEE Transactions on Power Electronics, vol. 18, no. 1, pp. 65-73, 2003.

[18] S. Haykin, Neural Networks A Comprehensive Foundation, Pearson Education, Singapore, 9th edition, 2005.

[19] J. J. Hopfield and D. W. Tank, "'Neural' computation of decisions in optimization problems," Biological Cybernetics, vol. 52, no. 3, pp. 141-152, 1985.

[20] A. T. Azar, Fuzzy Systems, Intech, Vukovar, Croatia, 1st edition, 2010. 


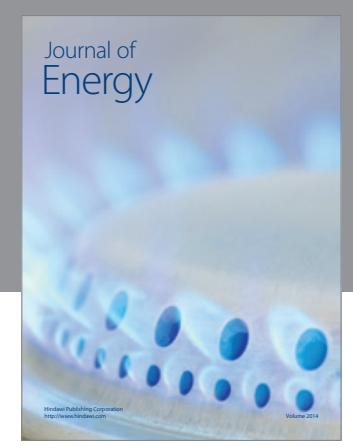

Journal of

Industrial Engineering
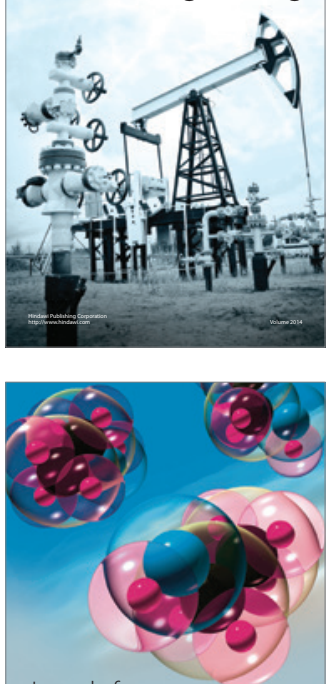

Fuels
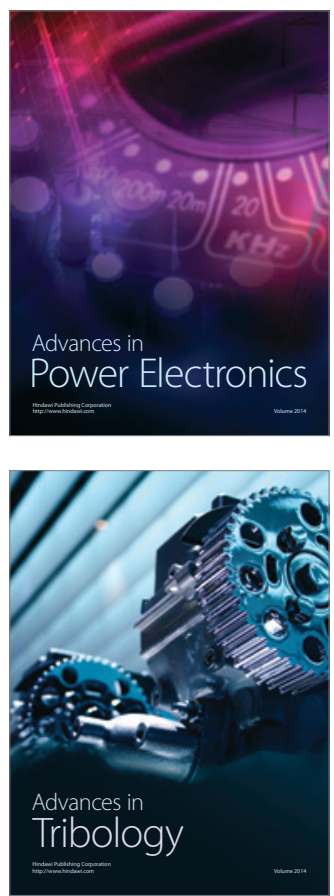

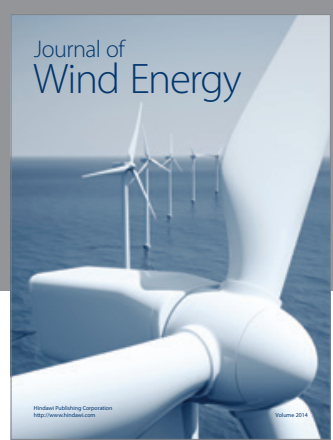

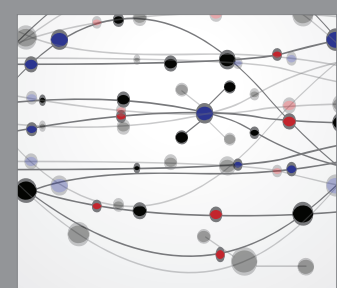

The Scientific World Journal

Submit your manuscripts at http://www.hindawi.com

Journal of

Structures
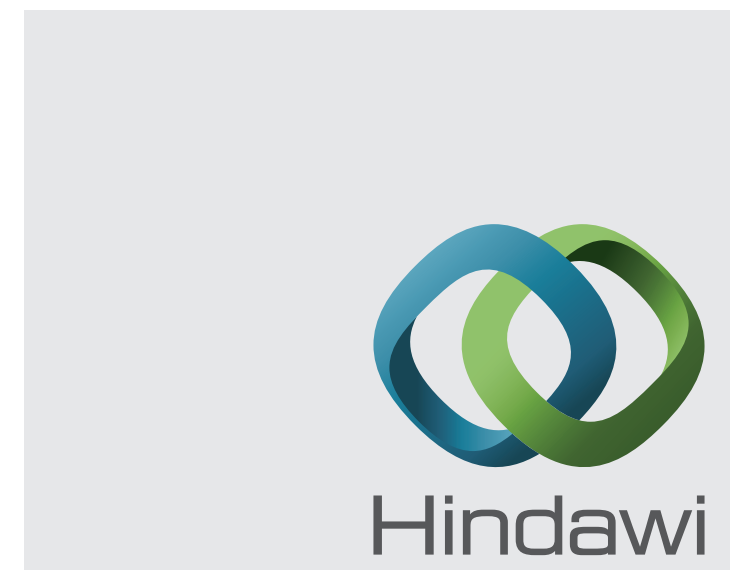

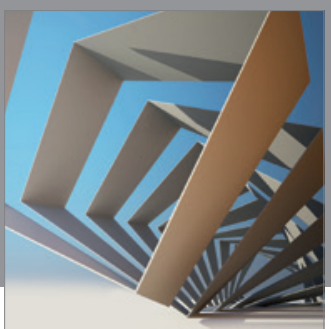

Rotating

Machinery
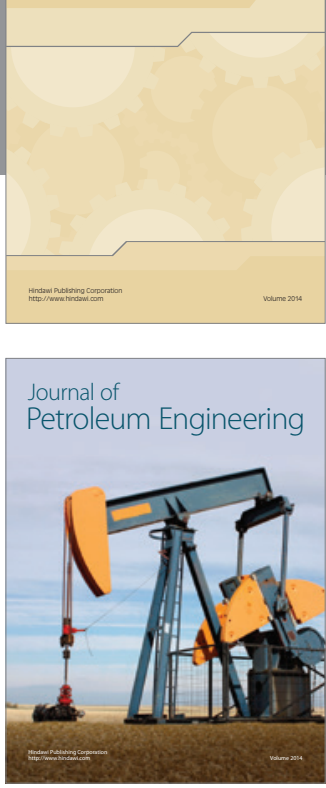

Journal of

Solar Energy
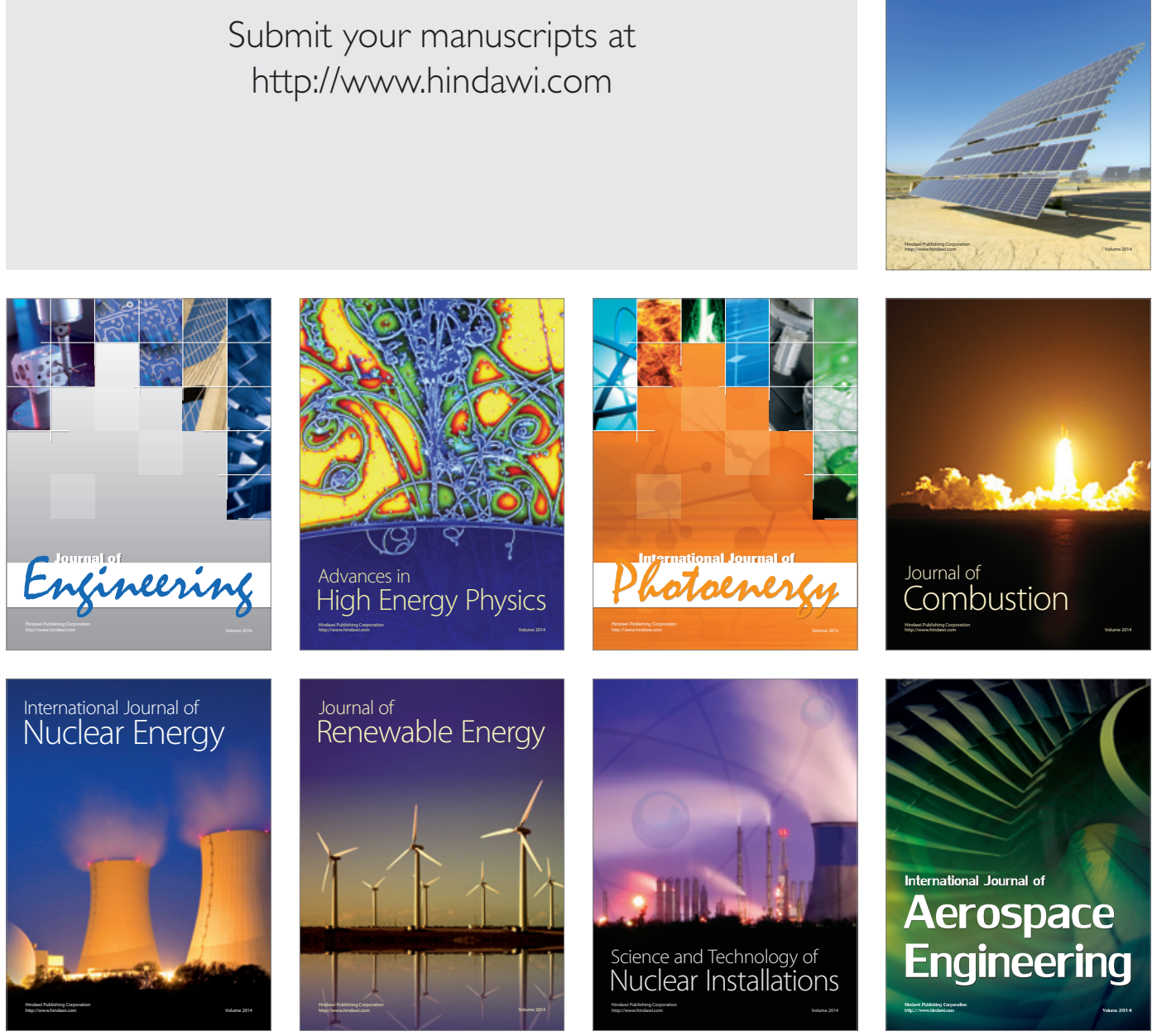